\title{
POSIÇÕES SUBJETIVAS EM FACE \\ DA VIOLÊNCIA: \\ TRAÇOS CONSTITUTIVOS \\ DE MEMÓRIA \\ EM TESTEMUNHOS \\ DE MULHERES
}

\section{POSICIONES SUBJETIVAS DELANTE DE LA VIOLENCIA: TRAZOS CONSTITUTIVOS DE MEMORIA EN TESTIGOS DE MUJERES}

SUBJECTIVE POSITIONS IN THE FACE OF VIOLENCE: CONSTITUTIVE MEMORY TRACES IN WOMEN'S TESTIMONIES

Aline Fernandes de Azevedo Bocchi*

USP | Universidade de Franca

RESUMO: Apresenta-se, neste artigo, uma reflexão acerca dos processos de subjetivação inscritos na prática testemunhal, a partir do exame de fotografias que compõem o "Projeto 1:4 retratos da violência obstétrica" e posts que o divulgam no Facebook. Por meio de uma abordagem discursiva, são analisadas as posições subjetivas inscritas neste material, voltando a atenção para as formas com as quais a violência é simbolizada na materialidade da língua e do discurso, produzindo um dizer político de denúncia da agressão e do abuso médicos. Na composição material tecida entre imagem e palavra, formulada no ensaio fotográfico, o testemunho se reveste de uma força performativa que acompanha os processos de transformação e deslocamento ideológicos, produzindo possibilidades de identificação para as mulheres em contraposição aos sentidos de naturalização da violência de gênero estrutural à sociedade patriarcal.

PALAVRAS-CHAVE: Testemunho. Violência. Fotografia. Corpo. Subjetividades.

\footnotetext{
* Mestra em Ciências da Comunicação pela ECA - USP, doutora em Linguística pelo IEL - UNiCAMP, com pós-doutorado e estágio no exterior na Université Paris 13 (financiado pela Capes). Foi bolsista Capes PNPD na Universidade de Franca. Atualmente, é bolsista Fapesp (proc. 2016/20876-6) no Programa Pós-graduação da Faculdade de Filosofia, Ciências e LetrasdeRibeirãoPreto - USP|El@dis.E-mail:azevedo.aline@gmail.com.
} 
RESUMEN: Presentamos, en ese artículo, una reflexión acerca de los procesos de subjetivación inscrito en la práctica testimonial, a partir del examen de fotografías que compone el Proyecto 1:4 retratos de la violencia obstétrica y posts que lo divulgan en Facebook. Por medio de un abordaje discursivo, analizamos las posiciones subjetivas inscritas en ese material, poniendo nuestro interés para las formas con las cuales la violencia se simboliza en la materialidad de la lengua y del discurso, produciendo un decir político de denuncia y agresión y de abuso médico. En la composición tejida entre imagen y palabra, formulada en el ensayo fotográfico, el testimonio se reviste de una fuerza performativa que acompaña los procesos de transformación y desplazamiento ideológicos, produciendo posibilidades de identificación para las mujeres en contraposición a los sentidos de naturalización de la violencia de género estructural a la sociedad patriarcal.

PALABRAS-CLAVE: Testimonio. Violencia. Fotografía. Cuerpo. Subjetividad

ABSTRACT: In this article, we present a reflection on subjectivation processes inscribed in witness practice from examining photographs that comprise the "Project 1:4 pictures from obstetric violence" and posts that publicise this on Facebook. Using a discursive approach, we analyse the subjective positions found in this material, turning our interest to ways in which violence is symbolized in the materiality of language and discourse, producing a political speech of reporting aggression and doctor's abuse. In the material composition woven between image and word, formulated in photo essays, the witness is of a performative force that accompanies the transformation processes and ideological shift, producing identification possibilities for women as opposed to naturalization senses of structural gender violence to the patriarchal society.

KEYWORDS: Testimony. Violence. Photography. Body. Subjectivities.

\section{INTRODUÇÃO}

Amuralhar o próprio sofrimento é arriscar que ele te devore desde dentro. (Frida Khalo)

Investigamos, neste artigo, posições subjetivas de mulheres em face da violência, através do exame de testemunhos de partos traumáticos inscritos no ensaio fotográfico "1:4 retratos da violência obstétrica”. Em sua página no Facebook, focalizamos a fotografia de capa que ilustra a fanpage, além dos efeitos de autoria e leitura presentes em um de seus posts. Examinamos, também, algumas fotografias que compõem o projeto, considerando especificamente a narratividade constitutiva dessas imagens. De autoria da fotógrafa Carla Raiter e da produtora cultural Caroline Ferreira, o projeto intenta materializar as marcas da violência médica através da fotografia. Ele nasceu a partir do resultado de um estudo efetuado pela Fundação Perseu Abramo (FIOCRUZ, 2010), cuja síntese explicita que "uma em cada quatro mulheres brasileiras que deram a luz em hospitais públicos e privados relatam algum tipo de agressão durante o parto". O ensaio circulou na web em blogs e sites que defendem os direitos reprodutivos das mulheres, e foi divulgado no caderno Foto Cotidiano da versão online do jornal Folha de S. Paulo de 12/03/2014 (VIOLÊNCIA, 2014). Ele retrata corpos submetidos à violência no momento do parto e cuja carne expõe inscrições: uma memória viva que presentifica um momento de agressão, dor e sujeição da mulher. Nosso gesto de interpretação irá se deter em cinco recortes extraídos deste material. Esclarecemos que, na perspectiva teórica à qual nos filiamos, o recorte é compreendido como uma unidade discursiva, ou seja, "[...] fragmentos correlacionados de linguagem-em-situação. Assim, um recorte é um fragmento da situação discursiva [...] que remete à polissemia e não à informação" (ORLANDI, 1984, p. 14).

O referencial teórico da análise de discurso (PÊCHEUX, 2010; 2009; 2008), em sua articulação com a psicanálise, sustenta as análises realizadas, cujo objetivo é deflagrar processos de resistência que desestabilizam identificações para as mulheres sustentadas em práticas que naturalizam a violência, por meio de um efeito desregulariza-dor produzido pelos discursos de denúncia. Compreendidos enquanto acontecimentos, esses testemunhos se produzem em condições que perspectivam uma ocupação política do espaço digital, pois inscrevem lugares de enunciação(ZOPPI-FONTANA, 2001) que modificam os regimes de enunciabilidade de modo a possibilitar a circulação positiva, legítima e pública de sentidos outros para significar a mulher, perturbando e reorganizando identificações historicamente determinadas. Confrontadas com o real da violência obstétrica, essas mulheres expõem seus corpos e suas histórias, inscrevendo, por meio do ensaio fotográfico, gestos de resistências a um saber médico que as instrumentaliza. Ao retratar o momento do nascimento de uma criança como evento traumático, essas foto-narrativas assumem um funcionamento 
testemunhal, ou seja, se constituem como testemunhos de uma experiência de violência. Nosso olhar se volta, assim, para a compreensão do testemunho como forma pela qual a mulher inscreve uma posição subjetiva ao narrar o parto e a dor, e é dele que iremos nos ocupar. O que dizem as palavras das mulheres que experimentaram a experiência da violência em seus corpos? Como a dor e o desamparo são inscritos na materialidade da língua? E na materialidade da fotografia, em sua composição material e simbólica? São questões que nos convidam à escuta.

Interessa-nos compreender os processos de formulação, constituição e circulação do ensaio fotográfico, nos quais os dizeres de mulheres fotografadas foram impressos em seus corpos como modo de presentificar a violência sofrida. O corpo passa a ser, nestas formulações, o suporte de textualização de curtos relatos que produzem um efeito de síntese do evento traumático de violência médica. Ao incorporar o relato verbal de violência, a inscrição textual aliena o sujeito de seu corpo, introduzindo nele a fissura da diferença escritural. Isso porque a inserção da letra no corpo do sujeito marca esse corpo como irremediavelmente inscrito no simbólico, constituindo-o, portanto, na relação com o imaginário e o real. O que equivale a dizer, conforme Souza (2006), que "[...] só há subjetividade e corporeidade no plano da linguagem". O que, na interpretação discursiva, consiste em convocar o simbólico: sujeito e corpo são, pois, efeitos de linguagem, constituídos em sentidos que se tecem no/pelo simbólico.

Textualizados na materialidade da fotografia, esses testemunhos se encontram relacionados aos abusos do Estado e à crítica da violência contra a mulher. A violência contra a mulher se apresenta como um tema de relevância social incontestável e é atualmente objeto de discussões nas esferas públicas tanto no Brasil quanto em outros países. Para Heleieth Saffioti (1994), a violência contra a mulher é constitutiva da organização social de gênero: ela é um modo fundamental de regulação das relações sociais. Trata-se, para a autora, de uma "[...] modalidade material de controle social e da repressão" exercida através de um processo ideológico violento de "domesticação das mulheres" no qual "a violência constitui elemento fundamental de enquadramento da mulher brasileira no ordenamento social de gênero" (SAFFIOTI, 1994, p. 452). Em um texto emblemático no campo dos estudos de gênero no Brasil, escrito há pouco mais de vinte anos, Saffioti (1994, p. 444) nos presenteia com um direcionamento interpretativo acerca da violência inscrita nas relações de gênero: "fazendo-se uma leitura feminista dos direitos humanos, parece possível pensar, simultaneamente, a igualdade e a diferença”.

Embora a autora trate prioritariamente da violência doméstica e sexual praticada contra a mulher, o modo como ela problematiza as relações de gênero fornece um ponto de partida para pensar a violência na sua relação com o Estado. Segundo ela, "[...] o Estado não somente acolhe o poder masculino sobre a mulher, mas o normatiza, proibindo seus excessos" (SAFFIOTI, 1994, p. 445). Ele integra o "poder disciplinador da dominação sobre a mulher", ratificando sua dimensão material através da "forma jurídica que caracteriza a dominação legalizada”. Isso nos permite afirmar, recorrendo a Althusser (1985), que há um processo de legitimação social da violência sustentado por uma ideologia e garantido no modo de funcionamento do Estado ${ }^{1}$. Citando Saffioti (1994, p. 461): "Aparentemente, a ideologia é insidiosa, enquanto a violência é brutal. Um exame mais detido, entretanto, revela que ambas podem ser sutis e insidiosas, da mesma forma que brutais". No que diz respeito à violência obstétrica, a relação com o Estado é ainda mais problemática, pois a ele é imputada a procedência do gesto violento, embora isso não se dê a despeito de contradições: a responsabilização do indivíduo em detrimento do Estado se dá a ver na definição presente no documento da Defensoria Pública do estado de São Paulo (2013), "a violência obstétrica existe e caracteriza-se pela apropriação do corpo e processos reprodutivos das mulheres pelos profissionais da saúde". Ela se realiza através do "tratamento desumanizado, abuso da medicalização e patologização dos processos naturais, causando a perda da autonomia e capacidade de decidir livremente sobre seus corpos e sexualidade". Reconhecida como crime em países como a Argentina e a Venezuela, essa forma de violência carece de legislação mais efetiva no Brasil, embora tenhamos testemunhado atualmente algumas tentativas legais de contê-la².

\footnotetext{
${ }^{1}$ Althusser (1985) considera que o mecanismo ideológico de sujeição existe sob um conjunto de práticas, rituais que têm relação com instituições concretas, isto é, com os aparelhos ideológicos de Estado, que conferem unidade aos efeitos ideológicos produzidos por esse mecanismo de sujeição. Isto quer dizer que defender a tese da existência material das ideologias é recusar uma posição na qual a ideologia estaria presente nas ideias, é defender que a ideologia tem relação com o conjunto de práticas materiais necessárias à reprodução das relações de dominação em uma formação social.

${ }^{2}$ Em referência às novas regras estabelecidas pela Agência Nacional de Saúde Suplementar (ANS), que obriga os planos de saúde particulares a divulgarem os percentuais de cirurgias cesáreas e partos normais de hospitais e médicos conveniados. Elas foram alvo de polêmica entre as militantes, que sustentaram posições contra e a favor à regra que desobriga os convênios ao repasse de pagamento em casos de cesáreas desnecessárias. Evidentemente tais regras não garantem o acesso a um serviço de saúde respeitoso e não violento por parte da grande maioria da população brasileira.
} 


\section{CORPO, FOTOGRAFIA E NARRATIVIDADE}

Diante deste material, algumas questões se impõem. A primeira delas diz respeito a especificidade analítica que distintas materialidades significantes demanda: a imagem e a palavra, que compõe o tecido das fotografias; e o próprio ensaio fotográfico em si, compreendido aqui como um gesto de escuta de um corpo cindido pela violência. Neste percurso, um conceito que nos orientou foi o de composição material, delineado por Suzy Lagazzi (2012) como forma de apreender a relação que se estabelece entre distintas materialidades significantes. Ela diz: "[...] quando falo de imbricação material não se trata de complementariedade, não se trata de termos materialidades significantes que se complementam, mas sim materialidades significantes em composição, que se entrelaçam na contradição, 'cada uma fazendo trabalhar a incompletude da outra”. E acrescenta: “[...] imbricar pode ser compreendido, então, como compor no movimento da incompletude e da contradição" (LAGAZZI, 2012, p. 1).

A composição material e simbólica formulada no ensaio fotográfico possibilita, então, uma reflexão sobre os processos de identificação de gênero, cujo funcionamento sustenta o reconhecimento do grupo neste processo de produção identitária que, paradoxalmente, encobre a inquietante estranheza do desconhecido que nos habita, o impossível da identidade: "A mulher não existe”, advertia Lacan (2008b). Isto é, não existe a mulher, pois a mulher não é toda. Ainda falta. Ou, como comenta Betty Fuks (2014, p. 44) sobre a não identidade consigo mesma paradigmática da feminilidade (e não apenas dela), o tornar-se mulher implica considerar a impossibilidade de um ser final, pois "não há a mulher na qual o sujeito se transforma, mesmo quando se é mulher”.

Assim, neste processo discursivo (PÊCHEUX, 2010), somos interpelados pelo discurso testemunhal, através da identificação com a causa do projeto e com o grupo político que ele defende e representa. "Aquele que testemunha decidiu transformar o seu sofrimento em uma causa, posição que não deixa de ter como visada a fundação de um agrupamento social por via da identificação a um traço", considera Leite (2006, p. 180). A testemunha solicita nosso olhar e nossa cumplicidade, pela intimidade explicitada, produzindo um laço social que se assemelha a uma política solidária. A identificação com o grupo se dá por meio de um traço que constitui um corpo gendrado, ou seja, um corpo constituído historicamente como mulher, e essa constituição em corpo-mulher acontece por meio da violência de gênero. Ela o marca como corpo subordinado às formas de opressão do saber médico. Não é, portanto, o biológico ${ }^{3}$ que determina e constitui esse corpo, mas o histórico, ou seja, ele se constrói por meio de práticas históricas de agressão, abuso e coação.

Esses testemunhos perfazem, assim, movimentos de sentidos que vão do desejo de sutura à cicatriz de um trauma, e devem ser compreendidos não apenas na sua relação com o inconsciente, mas como um "sintoma da história" (CARUTH apud FELMAN, 2014, p. 31). Neste processo discursivo, a escrita inscreve no corpo uma narratividade, significando-o a partir de um processo de contra-identificação (PÊCHEUX, 2009) com a violência. Compreendemos narratividade segundo Orlandi (2016), que a desloca de uma definição circunscrita à tipologia clássica para situá-la na relação com os processos identitários, aqueles cujo reconhecimento se dá em espaços de interpretação determinados, consoantes a específicas práticas discursivas. É assim que compreendemos o ensaio fotográfico, como prática discursiva que oferece outra versão para um dizer de violência, uma versão que não silencia, mas expõe, acusa, delata.

\footnotetext{
${ }^{3}$ Neste estudo, a constituição do corpo-mulher e da direção dos processos de identificação e reconhecimento não é atribuída ao biológico também a partir do campo da psicanálise. Isso porque fazemos, consoante Lacan, uma leitura dos ensinamentos de Freud sustentada no conceito de "pulsão" como determinante da psique humana, diferente portanto de leituras que tomam a Trieb como "instinto sexual" e que favorecem uma leitura biologizante, enfatizando consequentemente as "fases do desenvolvimento" (fase oral, anal, etc.). Para Roudinesco \& Plon (1998), Lacan, ainda nos anos 1930, propôs um retorno aos textos de Freud com o intuito de tirar a psicanálise do ancoramento biológico. Em seu Seminário 11 - Os quatro conceitos fundamentais da psicanálise, Lacan lança uma questão: "Ora, aquilo de que se trata no que concerne à pulsão será do registro do orgânico?”. Para respondê-la, ele traça uma distinção entre a satisfação de uma necessidade orgânica e a satisfação pulsional, afirmando que o registro da necessidade fica fora do campo pulsional: "[...] essa boca que se abre no registro da pulsão - não é pelo alimento que ela se satisfaz..." (LACAN, 2008a, p. 165). Ele introduz, então, sua noção de objeto a.
} 


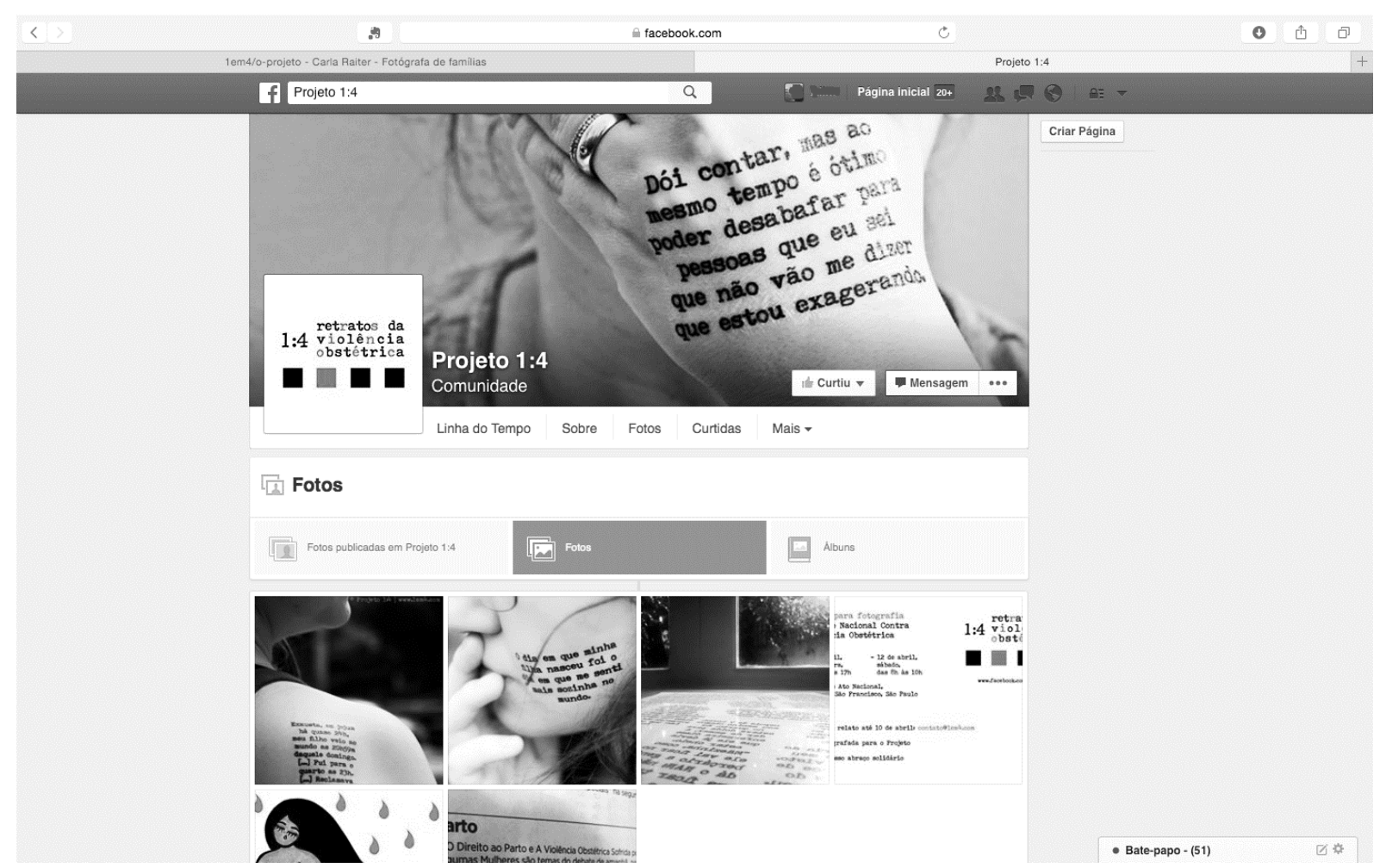

Figura 1: Página do Projeto 1:4 no Facebook

Fonte: Projeto 1:4 (2015)

Na fotografia de capa que ilustra a fan page do projeto (Figura 1), é possível reconhecer que a relação do desejo com a linguagem é uma relação de transferência: "Dói contar, mas ao mesmo tempo é ótimo poder desabafar para pessoas que eu sei que não vão dizer que eu estou exagerando". Nela, há um corpo sem rosto que comparece no gesto da mão cobrindo os lábios, simbolizando o choro contido. Impresso nesta mão que abafa o grito, o enunciado narra uma história de abuso. A discursivização da dor, possibilitada pela/na composição material da fotografia, aponta para um movimento na direção de uma cesura, da sutura (impossível) do trauma original, que embora nunca se cumpra, movimenta o sujeito em seu desejo.

A escrita marca esse corpo como corpo-outro, efeito do olhar do outro. É ela que institui a composição material fotográfica como testemunho, determinando a perspectiva do endereçamento, na relação com algo que não se pode calar. A escrita faz trabalhar a contradição específica da fotografia, ela permite a articulação deste discurso como trauma. A composição material vai além da mera função documental e jurídica do testemunho, seu funcionamento está focado em assegurar e atestar a veracidade do acontecido, pois admite e acolhe a expressão dos efeitos do abuso na subjetividade. Ela amplia os espaços de audição aos traumas sociais e pessoais de violência médica. Dito de outro modo, a composição material, urdida no encontro da imagem com a palavra, oferece uma escuta de uma subjetividade que se tece pelo testemunho. A composição simbólica produzida pelo ensaio fotográfico carrega em si as ambiguidades do testemunho: "[...] é testis, ou seja, fotografia-prova, atestação da verdade e, ao mesmo tempo, imagem da sobrevivência e do indizível: superstes" (SELIGMANN-SILVA, 2009, p. 322). Em seu papel de denúncia, são testemunhos que adquirem, aqui, um sentido forte, político, de engajamento crítico na mudança, e não um sentido meramente positivista que reafirma o poder da esfera jurídica.

Dito isso, é possível reconhecer dois gestos ${ }^{4}$ de simbolização distintos: tanto inscreve-se no corpo (pela escrita que nele se imprime) quanto o corpo (no clique fotográfico que o captura por meio de um enquadramento), textualizando-o e significando-o na composição material da fotografia. Esses gestos assinalam uma inevitável marca de alteridade, pois a experiência de um trauma

\footnotetext{
${ }^{4}$ Consideramos o gesto consoante Pêcheux (2010, p. 77) como "ato em nível simbólico", ou seja, como ato produzido em relação a um regime de sentido historicamente dado. Em nosso entendimento, tanto o clique do fotógrafo quanto a escrita são gestos simbólicos que demandam interpretações.
} 
demanda a escuta de um outro, além de dirigir-se ao grande Outro ${ }^{5}$, o que, segundo Felman (2014), implica uma dimensão humana e uma dimensão ética em que o Outro recebe prioridade sobre o eu. Em sua leitura da obra de Caruth, Felman mostra que essa dimensão ética está profundamente intrincada à questão da justiça. Segundo ela, Caruth explora como os textos da psicanálise, particularmente a obra de Freud Moisés e o Monoteísmo (no qual o testamento de Freud sobre a história como trauma comparece como lugar de inscrição de um trauma histórico), "[...] tanto falam sobre como falam por meio da profunda narrativa da experiência traumática" (CARUTH apud FELMAN, 2014, p. 31). Sua argumentação sustenta, portanto, o trauma não como simples gravação do passado, mas precisamente como forma de registro de uma experiência que não foi reclamada, que não foi reconhecida social e historicamente. Ela situa, assim, o trauma como evento constituído por sua falta de integração na consciência, no qual seu impacto tardio insiste em retornar, repetir-se persistentemente:

Assim como os pesadelos traumáticos de soldados que regressam e que, anos depois da guerra, continuam a se repetir, e assim revivem reiteradamente a dor, a violência, o horror e o inesperado da cena traumatizante original, também a história está, da mesma forma, segundo Freud, sujeita a formas compulsivas de repetições traumáticas (imemoriais ainda que comemorativas). Freud então mostra como a energia traumática histórica pode ser a força motriz da sociedade, da cultura, da tradição e da história em si (FELMAN, 2014, p. 31).

Assim, consoante Felman, consideramos que a naturalização da violência é produzida por meio da repetição como modo de funcionamento compulsivo do evento histórico de violência contra a mulher, "[...] sua persistência em retornar historicamente e repetir-se na prática e no ato, até o ponto preciso em que permanece irreconhecido e indisponível ao conhecimento e à consciência” (CARUTH, 1995 apud FELMAN, 2014, p. 31). Isso sugere que, no confronto com uma história que repetidamente violenta e oprime, o testemunho materializa, então, os equívocos que a constituem como lugar contraditório, pois afetam a univocidade linguística do sujeito, levando-o ao encontro do real histórico: "a irrupção do equívoco afeta o real da história" (PÊCHEUX, 1981, p. 62) justamente por conjurar o impossível (linguístico) à contradição (histórica).

\section{TESTEMUNHO E VIOLÊNCIA: NARRATIVIDADES DA DOR}

Neste trabalho, procuramos sustentar uma definição de testemunho como prática de linguagem na qual um acontecimento traumático é reelaborado e simbolizado na materialidade da fotografia, cuja composição material apresenta curtos relatos impressos nos corpos de mulheres que experimentaram formas de violência obstétrica. Tal prática discursiva consiste em um gesto de relatar e atestar uma experiência de parto, construindo sua narratividade, isto é, discursivizando a violência inscrita na experiência feminina de um parto vivido como evento violento. Isto nos leva a pensar que, ao se formular como testemunho de um acontecimento de violência impingido ao corpo da mulher, tais relatos de parto se constituem como tentativas de elaboração de um trauma que é da ordem do social, coletivo e histórico, já que lida com uma memória coletiva de violência. "A especificidade do indivíduo não existe jamais sozinha: é o grupo que a confere. Redescobrir a dimensão singular implica a reconstrução desta coletividade e de sua cultura pelos materiais da lembrança. Lá ainda o individual registra o coletivo”6 (WIEVIORKA, 2013, p. 48).

\footnotetext{
${ }^{5}$ Para Pêcheux (2009), o sujeito, quando diz "eu” (ego), o faz a partir de sua inscrição no simbólico, inserido portanto em uma relação imaginária com a "realidade", constituindo sua forma-sujeito (que, na sociedade capitalista, encarna a forma da autonomia e da responsabilidade). Essa relação imaginária o impede de reconhecer sua constituição pelo Outro, isto é, o sujeito não percebe que foi convocado a colocar-se no simbólico para dizer "eu”. É a anterioridade do simbólico que produz seu assujeitamento ao campo da linguagem. Ela tece uma relação de dependência do sujeito ao significante, produzindo-o como efeito, pois o ponto de partida é o Outro, isto é, o Outro da linguagem e da historicidade. O Outro designa, então, simultaneamente, tanto o grande Outro lacaniano (o simbólico, Outro da linguagem, o inconsciente como discurso do Outro), como o interdiscurso como exterioridade constitutiva do dizer: "o interdiscurso fornece 'a cada sujeito' sua 'realidade', enquanto sistema de evidências e de significações percebidas - aceitas - experimentadas” (PÊCHEUX, 2009, p. 150; MARIANI, 2003, p. 62). A questão ética, portanto, não pretere a responsabilidade do sujeito constituído em forma-sujeito. Ao contrário, ela está na forma-sujeito implicada.

6 "La spécificité d'un individu n'existe jamais seule: c'est le groupe qui la lui confère. Redécouvrir la dimension singulière implique la reconstruction de cette collectivité et de sa culture par les matériaux du souvenir. Là encore, l'individuel rejoint le collectif”. A tradução é minha.
} 
Assim, consideramos a violência contra a mulher como um lugar de inscrição de um trauma que é, sobretudo, histórico. "A história, como o trauma, nunca é simplesmente própria de um indivíduo, a história é precisamente a maneira em que estamos implicados nos traumas uns dos outros" (CARUTH, 1995 apud FELMAN, 2014, p. 31).

Para Leite (2006, p. 179), o testemunho consiste na experiência do impossível. A posição do sobrevivente de uma catástrofe (Shoah, em hebraico, filia-se ao sentido de catástrofe), daquele que decidiu narrar para testemunhar um acontecimento, está próxima, para a autora, das bordas do simbólico. Em uma análise do livro Fragmentos - memórias de uma infância 1939-1948, de Binjamin Wilkomirski, ela afirma que o traço que melhor caracteriza a literatura de testemunho é "[...] a tensão entre a necessidade de narrar e a necessidade de fazê-lo face ao reconhecimento da insuficiência e do fracasso da linguagem frente ao horror". Para a autora, o testemunho coloca em ato os limites do simbólico para dar conta do real. Ele sugere que "o simbólico nasce de um gesto de reescritura dolorosa do real”. Reconhecemos, então, a partir dos nossas análises, que a função do testemunho é fazer falar a dor, o sofrimento e o desamparo, conforme o segundo recorte (Figura 2): "O dia em que minha filha nasceu foi o dia em que me senti mais sozinha no mundo". Nele, a composição material, tecida entre imagens e palavras, produz o sujeito como efeito da violência experimentada, no desabafo possibilitado pela prática testemunhal.

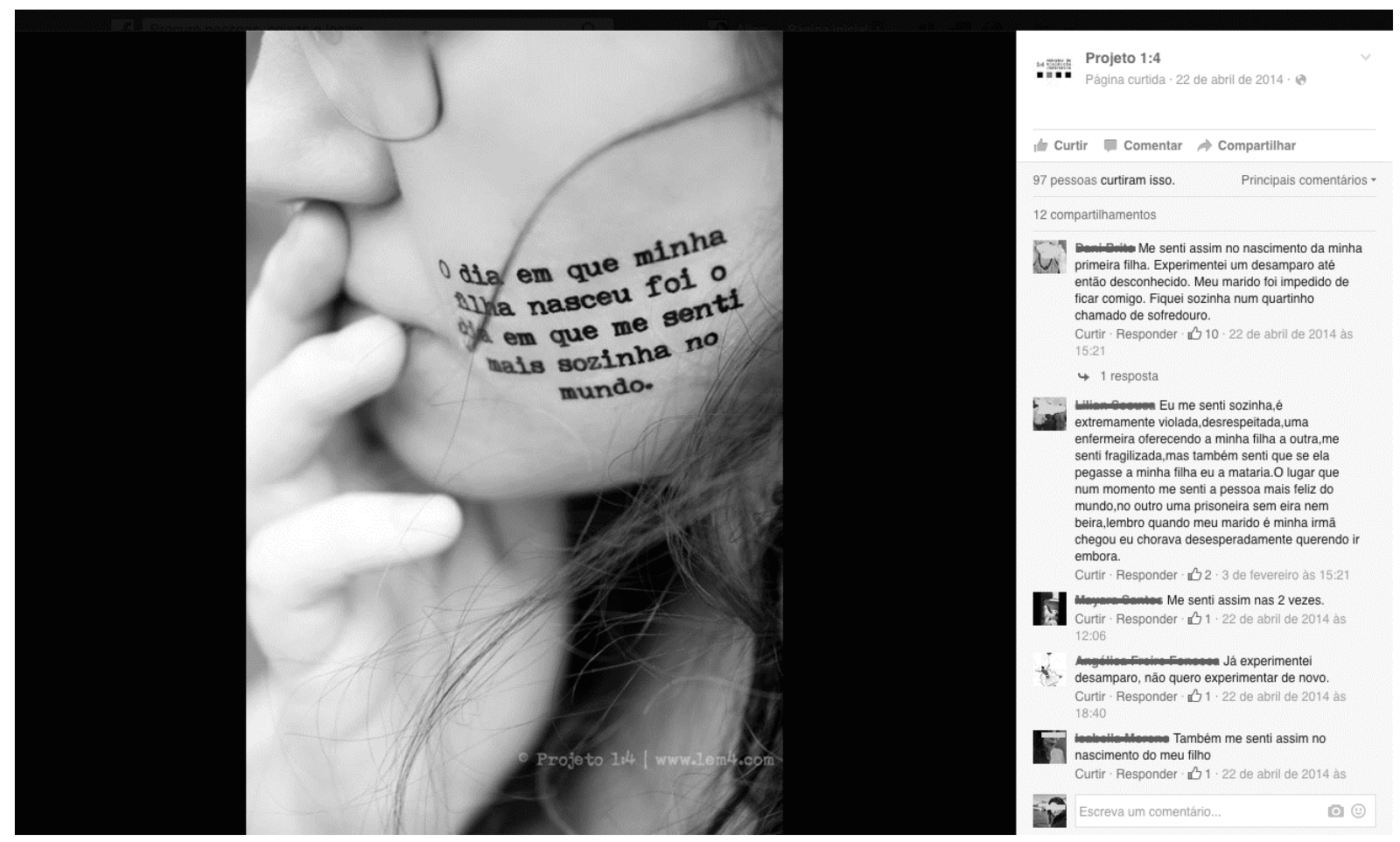

Figura 2: Página do Projeto 1:4 no Facebook

Fonte: Projeto 1:4 (2015)

O testemunho do sobrevivente, aponta Appelfeld (1932 apud SELIGMANN-SILVA, 2013, p. 20), é, antes de mais nada, a busca de um alívio. Nele, a escritura reinscreve uma memória de violência, mas também de resistência, pelo trabalho de luto que o testemunho possibilita. Para Maria Rita Kehl (2014, p. 18), o trabalho psíquico empreendido pelo enlutado consiste em um "[...] paulatino desligamento da libido em relação ao objeto de prazer que o ego perdeu, por morte ou abandono". Diante da ausência do objeto de desejo, o luto consiste no trabalho de elaboração da perda para que o ego possa encontrar novos investimentos e "voltar a viver”. A melancolia, neste processo, se inscreve simbolicamente como queixa ou acusação: a palavra alemã klage textualiza a dor para o melancólico, pela lamentação. Escrever sua experiência, dar testemunho dela, marca a importância do papel representado pelo melancólico como um sujeito que teria perdido seu lugar no laço social e sente necessidade de reinventar-se, no campo da linguagem. A aproximação entre luto e melancolia possibilitada na análise do recorte dá a ver a perturbação do sentimento de autoestima desses sujeitos que, em face da violência, perdem algo de si mesmos, isto é, se constituem na relação com um sentimento 
de perda em relação ao próprio corpo. Nessa direção, o ensaio fotográfico possibilita uma reinvenção de si e de seu corpo análoga ao trabalho do luto, afastando-se da lamentação puramente repetitiva do melancólico, já que traz também o sentido de acusação pública ou denúncia. Em outras palavras, no pensamento freudiano o luto consiste em um trabalho ambivalente sobre o objeto da perda, que se efetua através da incorporação da dor e da morte no discurso emancipatório testemunhal. Emancipatório tem, aqui, um duplo caráter: frente ao luto e frente à reivindicação de não violência.

Assim, tanto o ensaio fotográfico textualizado no post quanto seus efeito de leitura presentificados nos comentários apontam para um processo de reconhecimento de posições-sujeito em face da violência. Esse reconhecimento sugere que a repetição que aí se coloca não deve ser compreendida apenas na esfera do individual, da memória singular que insiste em retornar, mas da repetição histórica, de uma história que repetidamente violenta e oprime as mulheres, conforme verificamos na análise do próximo recorte. Nele, é possível ver que a experiência violenta encontra eco coletivo nos dizeres de sobreviventes, no trabalho do luto que visa reconstituir o objeto perdido e produzir um destino para a angústia (WIEVIORKA, 2013, p. 47).

\section{Projeto 1:4}

Página curtida $\cdot 22$ de abril de $2014 \cdot$ e

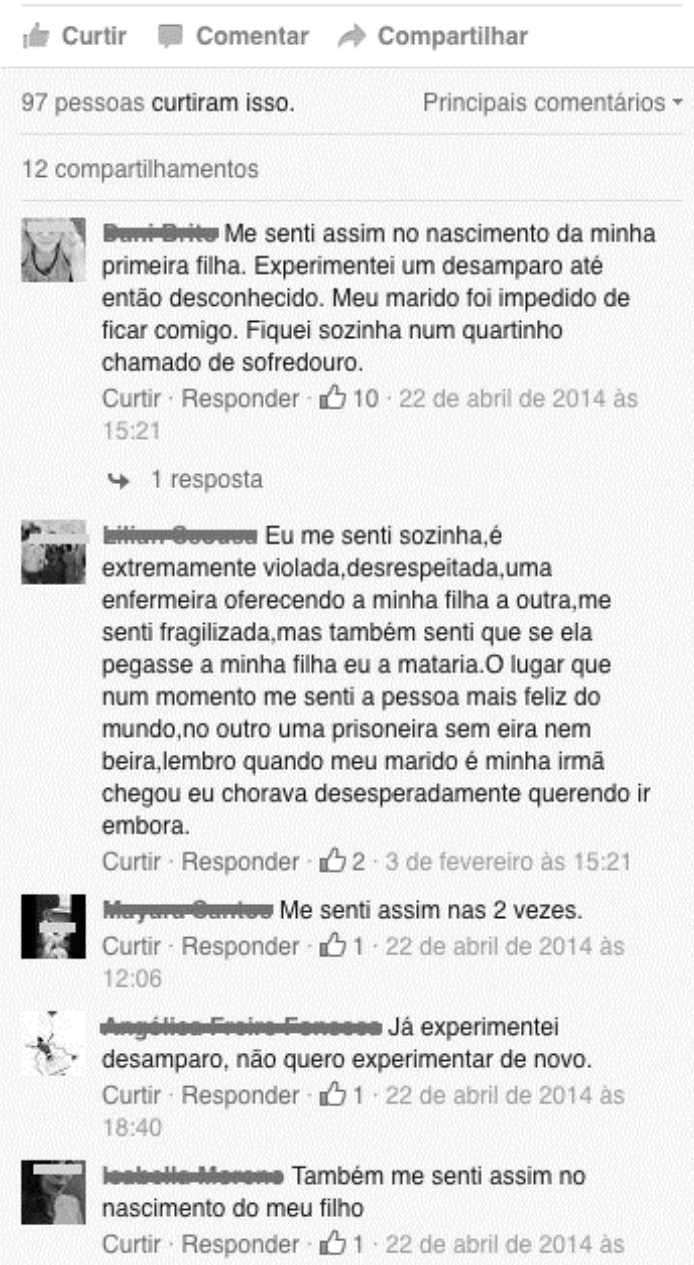

Figura 3: Comentários da postagem retratada na Figura 2

Fonte: Projeto 1:4(2015) 
Para Orlandi (2012), corpo textual e corpo subjetivo articulam-se inexoravelmente. Essa relação absolutamente necessária entre corpo da letra e corpo do sujeito torna-se visível nos dizeres que testemunham a violência, formulados nos comentários da postagem anterior (Figura 2). Nos deteremos, particularmente, ao primeiro comentário que ali figura (Figura 3):

Me senti assim no nascimento da minha primeira filha. Experimentei um desamparo até então desconhecido. Meu marido foi impedido de ficar comigo. Fiquei sozinha num quartinho chamado de sofredouro.

Neste recorte, a designação "sofredouro" nomeia a sala de parto como espaço significado pela dor, através da justaposição de dois nomes, "sofrimento" e "matadouro", que, no entanto, não possuem uma relação sintática evidente. O efeito de saturação do nome é produzido pela/na relação semântica, através do encaixe de dois nomes. Essa "escritura por encadeamento" ou "escritura de encaixe", conforme Pêcheux (1981), caracteriza-se por um dispositivo de construção de um nome no qual a união de duas palavras mantém conexões implícitas, ou seja, conexões construídas pelo/no interdiscurso. O que regula tal condensação e autoriza esse "encontro explosivo" é justamente a inscrição do sujeito da enunciação em uma formação discursiva, construindo a evidência do sentido do nome.

Esta desestruturação do léxico ${ }^{7}$ é, considerando Pêcheux (1990, p. 17), uma estratégia de resistência a uma prática de violência que se constitui no/pelo gesto que denuncia a animalização da mulher e de seu corpo pelas técnicas médicas de parturição. Aqui, "sofredouro" é a expressão do que, na enunciação, excede o léxico: a escrita faz corpo para o sujeito que narra, materializando, na palavra, o sofrimento. Esta desestruturação lexical, formulada na/pela emergência de uma palavra nova para dizer a incidência dos efeitos de uma situação real de violência que desumaniza a mulher, revela um "[...] processo metafórico em que o sentido passa a se produzir no interior do não-sentido" (GADET; PÊCHEUX, 2010, p. 65). Ela revela o equívoco exatamente no ponto em que o impossível linguístico vem aliar-se à contradição histórica; "o ponto em que a língua atinge a história" (p. 64), mostrando o poético lá onde comparecem inconsciente e ideologia.

\section{A CICATRIZ COMO TESTEMUNHO DA VIOLÊNCIA}

Ninguém nos corta a palavra da parede-do-coração (Paul Celan)

Segundo Orlandi (2012), é na formulação que a discursividade adquire visibilidade sintomática. Ou seja, é nela que encontramos vestígios de como o político significa esses corpos. No próximo recorte (Figura 4), a composição material da fotografia apresenta duas marcas que se sobressaem como formas de significar este corpo, a escrita e a cicatriz, que, entretanto, só podem significá-lo juntas, em relação, e não separadamente. A escrita no corpo funciona, neste e em outros recortes, como uma legenda, impondo uma orientação na leitura da imagem. Sozinha, essa imagem é muda ao trauma: é a escrita que delimita o quadro de interpretação do ensaio fotográfico como um todo. Ela possibilita, por assim dizer, a função de denúncia do projeto. Vejamos os dizeres que compõem este recorte:

Sua placenta está em grau 3. Eu recomendo que você agende uma cesárea hoje. Seu bebê está bem agora, mas a gente não sabe como vai estar daqui a pouco, e você sabe... seu bebezinho não quer morrer.

\footnotetext{
${ }^{7}$ Para Pêcheux, as resistências se ancoram na possibilidade de falha do ritual ideológico, e se materializam por meio das palavras. Ele diz: "[...] não entender ou entender errado; não 'escutar' as ordens; não repetir as litanias ou repeti-las de modo errôneo, falar quando se exige silêncio; falar sua língua como uma língua estrangeira que se domina mal; mudar, desviar, alterar o sentido das palavras e das frases; tomar os enunciados ao pé da letra; deslocar as regras na sintaxe e desestruturar o léxico jogando com as palavras[...]" (PÊCHEUX, 1990, p. 17).
} 


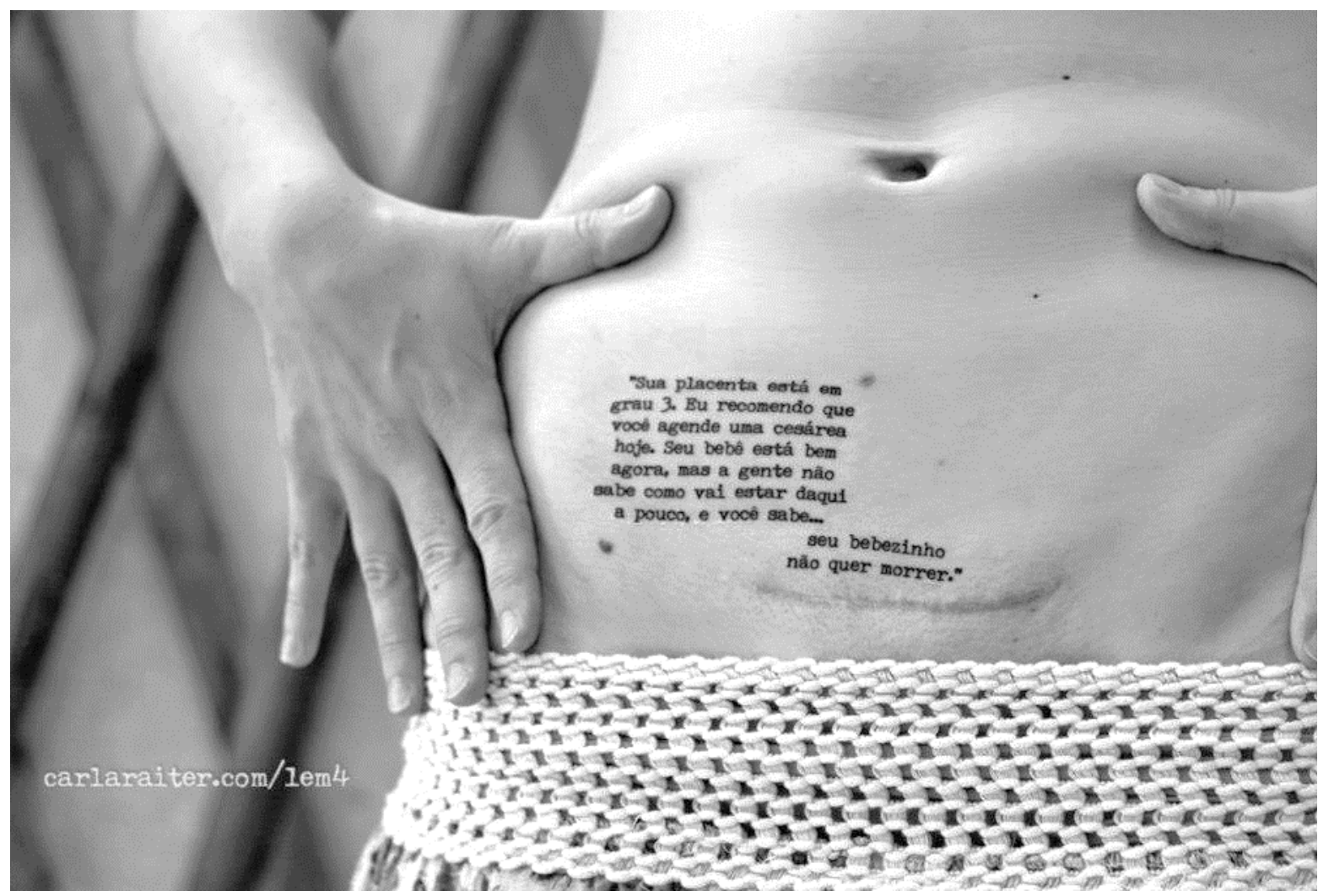

Figura 4: Um dos retratos que compõem o Projeto 1:4

Fonte: VIOLÊNCIA... (2014)

Nele (Figura 4), a escrita narra a violência a que esta mãe foi submetida através de uma fala relatada, a do médico, marcada linguisticamente por meio de aspas e, também, pelo emprego de pronomes possessivos ("sua placenta”, “seu bebê”, "seu bebezinho”),

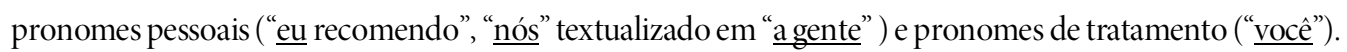

Consideramos que a escrita se constitui num espaço simbólico, lugar de interpretação, tecido pelo trabalho entre memória e esquecimento na constituição de subjetividades. Para Schons e Grigoletto (2008, p. 597), é pela/na escrita, tomada como prática social, que os sentidos se legitimam, resultado da relação entre leitor e autor sócio-historicamente constituídos: “[...] a escrita carrega traços constitutivos de identidade, por isso produz marcas, cicatrizes nos sujeitos que participam dessa experiência”. As autoras compreendem o testemunho como processo de estruturação do discursivo ancorado no trabalho da memória, na relação de transversalidade com os eixos do interdiscurso e do intradiscurso. É na verticalidade do interdiscurso que os sentidos se constituem em relação aos saberes presentes e ausentes, rememorados e esquecidos, que aparecem sob a forma de pré-construídos e sustentam o funcionamento do discursivo (PÊCHEUX, 2009). Ao eixo da horizontalidade corresponde o intradiscurso, o fio do discurso, lugar da formulação no qual, sob o manto da evidência, na dissimulação das condições de produção, operam as contradições.

Assim, considerando o fio do discurso, é no funcionamento das reticências, sinal de pontuação que marca a interrupção, que o efeito da violência, por meio de um dizer posto em suspenso, é produzido. Na formulação "você sabe...seu bebezinho não quer morrer", as reticências sinalizam, na incompletude, a suspensão de um dizer, momento no qual o sujeito hesita frente ao abismo do indizível. Lugar de silêncio rompido por uma fala de advertência, dizer de coação funcionando por intermédio do medo. Na composição tecida na materialidade fotográfica, entre imagem e palavra, a cicatriz sinaliza a decisão tomada em face da coação e do medo de perder seu filho, simboliza a vulnerabilidade de um corpo submetido ao saber médico e apropriado por suas técnicas.

Ambas as marcas, escrita e cicatriz, cravadas no intradiscurso, dizem a mulher do lugar de vítima de violência médica. Entretanto, trata-se de uma discursividade na qual a vítima denuncia seu algoz, em formulações afetadas pela história. Em outras palavras: o 
ensaio fotográfico, enquanto gesto de simbolização da dor, possibilita inscrições subjetivas outras, abre espaço para que essas mulheres signifiquem o trauma e a violência, permitindo que elas cumpram seu fardo ético de sobrevivência. Aqui, a escrita e a cicatriz são materialidades com distintos funcionamentos significantes: na primeira, o testemunho se dá pela palavra; na segunda, é o próprio corpo que testemunha de forma conclusiva, por meio da cicatriz como marca visível da memória do trauma cravada na carne.

A cicatriz constitui, assim, um significante em deriva, no processo de transferência, fazendo "passar" algo da experiência do sujeito, transferindo sentidos. Se para a psicanálise a transferência é incontornável à análise, na composição material e simbólica das fotografias as cicatrizes sinalizam para um real histórico de violência: elas são marcas que simbolizam a condição feminina em uma sociedade que naturaliza a violência contra a mulher. O efeito metafórico, para a análise de discurso, é compreendido como transferência, processo no qual algo que significava de um modo desliza para produzir outros efeitos de sentido (ORLANDI, 2012). Vejamos como funciona a produção de sentidos para o corpo da mulher no gesto de interpretação do próximo recorte (Figura 5), no qual a cicatriz também comparece na composição da imagem:

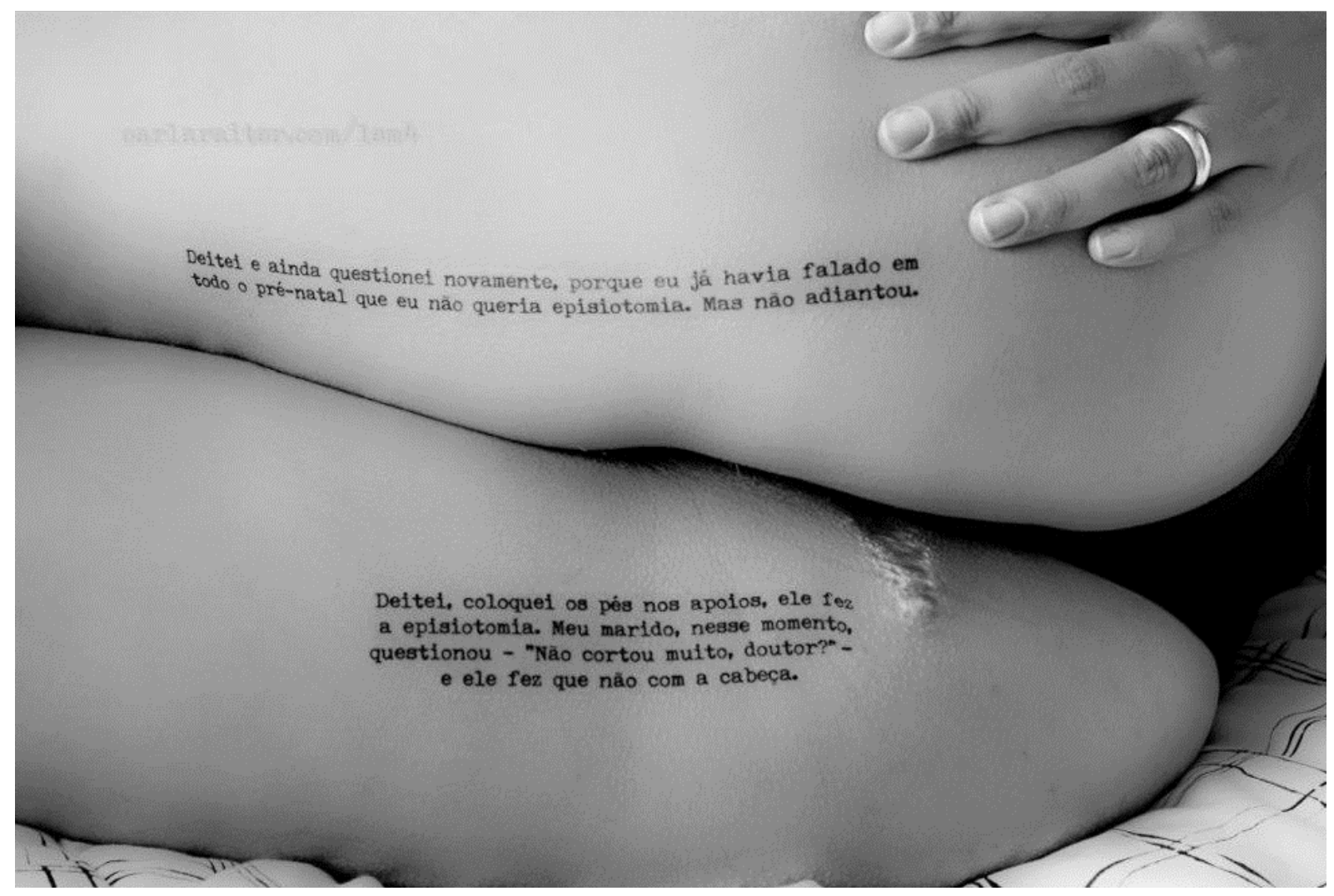

Figura 5: Retrato do Projeto 1:4

Fonte: VIOLÊNCIA... (2014)

Ao vislumbrar este recorte (Figura 5), podemos compreender como a estruturação do discursivo vai constituir a materialidade de uma certa memória social. Nos sentidos que escrita e cicatriz, juntas, produzem, a memória reconstrói o momento do trauma para esse sujeito. Sua denúncia, entretanto, o amplifica, constituindo-o, pelo endereçamento ao outro, enquanto trauma social e coletivo. Parafraseando Davallon (2007, p. 24), a imagem contemporânea funciona como um "operador da memória social", por meio da circulação dos objetos culturais. No enquadramento interpretativo da escrita-legenda a desenhar suas margens, a imagem presentifica, no modo como expõe a cicatriz, uma memória individual que não silencia, transformando-se, assim, em uma narrativa de superação que remete à força vital da imagem fotográfica. Entretanto, pela forma como produz sentidos, esse estigma de violência excede o que seria da ordem do singular, pois se filia a uma memória discursiva de violência de gênero. 
Lembrando Pêcheux (2007, p. 50), a memória deve ser entendida fora do domínio psicologista da memória individual, "[...] mas nos sentidos entrecruzados da memória mítica, da memória social inscrita em práticas, e da memória construída do historiador”. A cicatriz comparece, pois, como marca de um acontecimento que abandona o lugar da indiferença, recusa um domínio de insignificância ao fazer ecoar uma prática de violência de gênero inscrita em uma memória discursiva traumática. Ela é a inscrição do real da violência de gênero neste corpo, marca na carne da condição de ser mulher. Ao suspender o tempo passado congelandoo no presente, a cicatriz revive uma memória que não pode ser esquecida e que é atravessada por um enigma de sobrevivência: "o legado da experiência traumática impõe uma reflexão sobre e fornece um novo tipo de percepção da relação entre destruição e sobrevivência”, diz Felman (2014, p. 31). A cicatriz funciona como equívoco, lugar da hiância. Nela se presentificam sentidos de uma memória traumática. E nela, também, abre-se o sentido do trauma em direção à sobrevivência, pela denúncia de um corpo que insiste em resistir. Repetição e deslocamento. A cicatriz, estigma médico, assinala também a possibilidade de deriva.

\section{CONSIDERAÇÕES FINAIS: COMO PRODUZIR, DA VIOLÊNCIA, SENTIDOS?}

Consideramos, neste trabalho, a materialidade do ensaio fotográfico analisado, compreendido como espaço político de inscrição subjetiva, isto é, espaço de produção de sentidos outros para simbolizar a violência e a dor. A seguinte questão nos encoraja: como produzir, da violência, sentidos? O ensaio fotográfico configura, pois, uma possibilidade, no jogo da cadeia significante, de deslocar sentidos, metaforizando a violência. Ele funciona como linguagem em ato, capturando fragmentos de corpos e subjetividades inconclusas, produzindo uma forma de reinvenção desses corpos: ao capturá-los e textualizá-los na materialidade da fotografia, o ensaio fotográfico funciona como lugar no qual corpo e escrita se imbricam em consonância com um processo subjetivo inacabável.

Em sua interpretação dos estudos de Benjamin, Márcio Seligmann-Silva (2009, p. 303) considera que a fotografia possui uma origem metonímica, visto tratar-se de uma inscrição feita pela luz: "o princípio da captura do mundo por meio de uma janela". Nela, como nas imagens do trauma, se unem transitoriedade e repetibilidade. Priorizando enquadramentos em close, os corpos são retratados como fragmentos de uma história de dor, cacos de memória que dão voz a um passado traumático. São corpos sem rostos, histórias sem nomes, subjetividades que se inscrevem na imagem.

A fotografia possui, então, uma capacidade espectral de captar presenças e ausências, pois nelas se materializam não apenas os estilhaços de corpos enquadrados, mas tudo aquilo que permanece em suas margens, significando pela ausência: as bordas da imagem, seu fora-de-campo. Elas são gestos, construções imagéticas com força performativa. O ensaio fotográfico se constitui, então, como ritual no qual as imagens são convocadas para permitir a reparação de uma perda. A composição material significante, no modo como formula a experiência da violência, testemunha um corpo que resiste às injunções impostas por um história tecida, predominantemente, por (e para) homens. Ela materializa um modo de reinvenção da experiência traumática. Não é, portanto, simples expressão da violência, pois nela habita o jogo necessário da metáfora a transferir sentidos (PÊCHEUX, 2010), no deslocamento incessante do significante.

Assim, testemunho, corpo e escrita se entrelaçam, no processo discursivo apreendido no ensaio fotográfico, do qual a fotografia captura um flagrante (ORLANDI, 2001), um modo próprio de aparição do corpo que procura apreender o real (inapreensível) da violência. Sustentamos, então, a compreensão de que os testemunhos têm uma dupla função. A primeira deriva da capacidade da escrita de reparar uma perda: a escrita é, na sua origem, a linguagem do ausente, comenta Freud (2015) em "O mal-estar na cultura". A segunda refere a disposição do testemunho em deslocar a memória social, produzindo rupturas com uma história marcada pela violência. Ambas as funções se amparam em uma conceituação particular do testemunho, que o define a partir de sua inexorável relação com o corpo: no testemunho de violência, o corpo como lugar paradoxal de sobrevivência imediatamente se coloca. É nele que algo se repete insistentemente. Eé nele que o acontecimento manifesta um "sopro de irregularidade".

Consideramos, então, o ensaio fotográfico como lugar em que uma escrita do corpo se formula, lugar de abertura para uma leitura de seus sintomas, das cicatrizes que constituem sua história. E, como sugeriu Pêcheux em uma nota de sua conhecida retificação à Les vérités de la Palice, é no corpo que algo fala/falha, é nele que "algo se fortalece contra a repetição e o nada".

Bocchi | Posições subjetivas em face da violência: traços constitutivosde memória em testemunhos de mulheres 


\section{REFERÊNCIAS}

ALTHUSSER, L. Aparelhos ideológicos de estado: nota sobre os aparelhos ideológicos de Estado (AIE). Trad. Walter José Evangelista e Maria Laura Viveiros de Castro. Rio de Janeiro: Edições Graal, 1985.

DAVALLON, J. A imagem, uma arte de memória? In: ACHARD, P.; DAVALLON, J.; DURAND, J-L.; PECCHEUX, M.; ORLANDI, E. Papel da memória. Trad. José Horta Nunes. Campinas: Pontes, 2007. p. 23 - 37.

SÃO PAULO (Estado). Defensoria Pública. Coordenadoria de Comunicação Social e Assessoria de Imprensa. Violência obstétrica. Você sabe o que é?. São Paulo, 2013. Disponível em: <http://www.defensoria.sp.gov.br/dpesp/repositorio/41/violencia\%20obstetrica.pdf>. Acesso em: 16 jul. 2016.

FELMAN, S. O inconsciente jurídico: julgamentos e traumas no século XX. Trad. Ariani Bueno Sudatti. São Paulo: EDIPRO, 2014. FREUD, S. O mal-estar na cultura. Trad. Renato Zwick. 2. ed. Porto Alegre: L\&PM, 2015.

FUKS, B. B. O homem Moisés e a religião monoteísta - três ensaios: O desvelar de um assassinato. Rio de Janeiro: Civilização Brasileira, 2014.

FIOCRUZ. Escola Nacional de Saúde Pública Sergio Arouca, Fundação Oswaldo Cruz. Projeto Nascer no Brasil: Inquérito Nacional sobre Parto e Nascimento, 2010. Disponível em: <http://www6.ensp.fiocruz.br/nascerbrasil> . Acesso em: 10 mar. 2014.

GADET, F. ; PÊCHEUX, M. A língua inatingível. Trad. Bethania Mariani e Maria Elizabeth Chaves de Melo. 2. ed. Campinas: Editora RG, 2010.

GRIGOLETTO, E.; SCHONS, C. R. Escrita de si, memória e alteridade: uma análise em contraponto. In: JORNADA INTERNACIONAL DE ESTUDOS DO DISCURSO, 1., Maringá, 2008. Anais eletrônicos... Maringá, 2008. p. 407-418. Disponível em: < http://www.dle.uem.br/jied/pdf/ESCRITA\%20DE\%20SI\%20schons\%20e\%20grigoletto.pdf>. Acesso em: 13 mar. 2016.

KEHL, M. R. Melancolia e Criação. In: FREUD, S. Luto e melancolia. São Paulo: Cosac Naify, 2011.

LACAN, J. Seminário, livro 11: os quatro conceitos fundamentais da psicanálise. Rio de Janeiro: Jorge Zahar, 2008a.

LACAN, J. Seminário, livro 20: mais, ainda. Rio de Janeiro : Zahar, 2008.

LAGAZZI, S. O exercício parafrástico na imbricação material. In: ENANPOLL, 27., Rio de Janeiro, 2012. Anais... Rio de Janeiro: [s.n.], 2012. Disponível em: <http://www.labeurb.unicamp.br/anpoll/resumos/SuzyLagazzi.pdf>. Acesso em: 26 jun. 2012.

LEITE, N. Escrita e transmissão da experiência. In: MARIANI, B. (Org.). A escrita e os escritos: reflexões em análise de discurso e psicanálise. São Carlos: Claraluz, 2006.p. 175 - 184. 
MARIANI, B. Subjetividade e imaginário linguístico. Linguagem em (Dis)curso, Tubarão, v. 3, Número Especial, p. 55-72, 2003.

ORLANDI, E. P. Segmentar ou recortar? Linguística: questões e controvérsias. Série Estudos 10. Curso de Letras do Centro de Ciências Humanas e Letras das Faculdades Integradas de Uberaba, 1984.

(Org.). Cidade atravessada: Os sentidos públicos no espaço urbano. Campinas: Pontes, 2001.

Discurso e texto. Formulação e circulação dos sentidos. 4. ed. Campinas: Pontes, 2012.

(Org.). Instituição, relatos e lendas. Narratividade e individuação dos sujeitos. Pouso Alegre: Editora RG, 2016.

PÊCHEUX, M. [1981] L'énoncé: enchâssement, articulation et dé-liaison. In: CONEIN, B. et al. (Ed.). Colloque Matérialités Discursives. Lille: Presses universitaires de Lille, 1981. p. 143 - 148.

Delimitações, inversões, deslocamentos. Trad. José Horta Nunes. Caderno de Estudo Linguísticos, Campinas, v. 19, p. 7 24, jul./dez., 1990.

. Papel da memória. In: ACHARD, P. et al. (Ed.) Papel da memória. Trad. José Horta Nunes. Campinas: Pontes, 2007. p. $49-58$.

O discurso: estrutura ou acontecimento. Tradução de Eni Orlandi. São Paulo: Pontes, 2008.

Semântica e discurso - uma crítica à afirmação do óbvio. Campinas: Editora da Unicamp, 2009.

Análise automática do discurso (AAD-69). In: GADET, F.; HAK, T. Por uma análise automática do discurso: uma introdução à obra de Michel Pêcheux. Tradução de Bethania Mariani et al. Campinas: Unicamp, 2010. p. 61-161.

PROJETO 1:4, Retratos da violência obstétrica. Comunidade Facebook, 2015. Disponível em: < https://www.facebook.com>. Acesso em: 12 abr. 2015.

ROUDINESCO, E.; PLON, M. Dicionário de psicanálise. Rio de Janeiro: Jorge Zahar, 1998.

SAFFIOTI, H. I. B. Violência de gênero no Brasil atual. Estudos Feministas, Florianópolis, Número Especial, v. 2, p. 443-461, 1994.

SELIGMANN-SILVA, M. Fotografia como arte do trauma e imagem-ação: jogo de espectros na fotografia de desaparecidos das ditaduras na América Latina. Temas em Psicologia. Dossiê "Psicologia, violência e o debate entre saberes”, Brasil, v. 17, n. 2, p. 311$328,2009$.

. Introdução. In: SELIGMANN-SILVA, M. (Org.). História, memória, literatura: o testemunho na Era das Catástrofes. Campinas: Editora da Unicamp, 2013.p. 7 - 44. 
SOUZA, P. Escrita e corpo: vestígios subterrâneos da subjetivação. Organon, Porto Alegre, n. 40/41, jan./dez., p. 1-314, 2006.

VIOLÊNCIA obstétrica. Mulheres relatam sofrimento antes, durante e no pós-parto. Folha de S. Paulo online. Foto Cotidiano. São Paulo, 12 mar. 2014. <Disponível em: http://fotografia.folha.uol.com.br/galerias/23593-violencia-obstetrica>. Acesso em: 13 mar. 2016.

WIEVIORKA, A. L’ère du témoin. Paris: Pluriel, 2013. 